\title{
BIOMARKER POTENTIAL OF IQ-DOMAIN GTPASE-ACTIVATING PROTEINS FAMILY PROTEIN IN PANCREATIC CANCER: A MINI REVIEW
}

\section{ANTON SUMARPO ${ }^{*}$, AGNES ANANIA TRIAVIKA SAHAMASTUTI², GISELLA EDNY TJUGIANTO², KENNY YONATHAN ${ }^{3}$, DAVID AGUSTRIAWAN ${ }^{4}$}

\begin{abstract}
${ }^{1}$ Department of Biochemistry, Faculty of Medicine, Atma Jaya Catholic University of Indonesia, Jakarta, Indonesia. ${ }^{2}$ Department of Pharmacy, Indonesia International Institute for Life Sciences, Jakarta, Indonesia. ${ }^{3}$ Department of Biomedicine, Indonesia International Institute for Life Sciences, Jakarta, Indonesia. ${ }^{4}$ Department of Bioinformatics, Indonesia International Institute for Life Sciences, Jakarta, Indonesia. Email: sumarpo01060715@gmail.com
\end{abstract}

Received: 28 February 2018, Revised and Accepted: 25 March 2018

ABSTRACT

Objectives: Our present study was done to understand molecular regulatory mechanisms of IQGAP proteins and their potentials as biomarker in pancreatic cancer.

Methods: In this review, relevant studies were obtained by assessing the PubMed database using the combination of words that included "IQGAP" and "pancreatic cancer".

Results: There is an increasing evidence showing that the expression of IQGAP1 and IQGAP3 is positively correlated with tumorigenesis; however, IQGAP2 might play a role to suppress tumor progression.

Conclusion: IQGAP proteins might have potentials as predictive and prognostic biomarker for human pancreatic cancer.

Keywords: Pancreatic cancer, IQ-domain GTPase-activating proteins, Tumor biomarker, Early detection, Prognostic value.

(C) 2018 The Authors. Published by Innovare Academic Sciences Pvt Ltd. This is an open access article under the CC BY license (http://creativecommons. org/licenses/by/4. 0/) DOI: http://dx.doi.org/10.22159/ajpcr.2018.v11s3.30021

\section{INTRODUCTION}

Pancreatic cancer is one of the most lethal and frequently occurring malignancies in the world; it contributes to the 5 -year prevalence of $99 \%$ in both males and females in Indonesia [1]. Pancreatic cancer is generally classified based on their cellular differentiation of the neoplastic cells and the macroscopic appearance of the tumor [2]. Pancreatic ductal adenocarcinoma is the most common types, contributing more than $90 \%$ of all pancreatic malignancies [2,3]. The modifiable risk factors of pancreatic cancer include smoking, obesity, alcohol consumption, and dietary factors; meanwhile, diabetes mellitus, chronic pancreatitis, and genetic factors are among the non-modifiable risk factors [4]. Surgical resection, in combine with chemotherapy and radiotherapy, is the only possible treatment method by far; however, around $15-20 \%$ of patients who undergo surgical resection, the 5-year survival remains very low; it did not exceed more than 20\% [3,5]. Moreover, only a minority of patients can undergo a curative operation after diagnosis, primarily because of unspecific symptoms and limitations in diagnostic methods $[3,6,7]$. In addition, targeted therapy using gemcitabine (GEM) in combination with erlotinib may only prolong survival rate on average 2 weeks to several months [8-10]; however, increasing evidence of GEM and erlotinib resistance might limit the effect of this chemotherapy. In spite of finding effective curative method remains to be the major research focus, there is an increasing urgency to investigate detailed molecular mechanisms of cancer progression to elucidate novel biomarker in pancreatic cancer.

IQ-domain GTPase-activating proteins (IQGAPs) comprise a family of multidomain scaffold proteins that present in distinct organisms ranging from Saccharomyces cerevisiae and Caenorhabditis elegans to Xenopus laevis and mammals and regulate diverse biological processes including cell-cell adhesion, cell migration, extracellular signals, protein trafficking, and cytokinesis [11-14]. IQGAP1, a 190-kDa protein, was discovered in 1994 and most well studied among other IQGAPs recently $[11,13,15]$. IQGAP2 shares $62 \%$ similarities in the amino acid sequence with IQGAP1 [16]; meanwhile, IQGAP3 was identified back in 2007 [17]. The similarities in domain composition of IQGAPs might raise potentialities to share molecular functions among IQGAPs in some signaling pathways (Fig. 1); however, deregulation of IQGAPs might promote the development of various diseases [11]. In addition, there is a mounting evidence, suggesting an involvement of IQGAPs in human carcinogenesis in various types of cancer including ovarian [18], gastric [19], esophageal [20], liver [21-25], colorectal [26], breast [27], and prostate cancer [28]. Several studies have implicated that the presence of IQGAPs in pancreatic cancer is evident and might be correlated with tumorigenesis [29-37]. In this review, we focus on the molecular mechanisms of IQGAPs and their potentials as biomarker for early detection and prognostic evaluation in pancreatic cancer.

\section{OVEREXPRESSION OF IQGAP1 AND IQGAP3 PROMOTE CELL MIGRATION AND INVASIONS IN PANCREATIC CANCER}

In 2011, our understanding of human cancer reached a new milestone when Hanahan and Weinberg et al. proposed that cancer cells should display 10 fundamental traits in cellular physiology to be able to promote growth and metastatic dissemination, known as the hallmarks of cancer [38] (Fig. 2). Therefore, investigating molecular mechanism of IQGAPs based on these hallmarks is essential to better understand their role in pancreatic cancer.

As previously mentioned, IQGAP1 is the best-characterized protein among IQGAP isoforms. In physiological condition, IQGAP1 regulates cadherin-mediated focal adhesion, cell motility and migration, and endocytosis [39-41]. Moreover, the diverse range of protein-protein interactions suggests that IQGAP1 is highly influential in signal transduction pathways including mitogen-activated protein kinase 


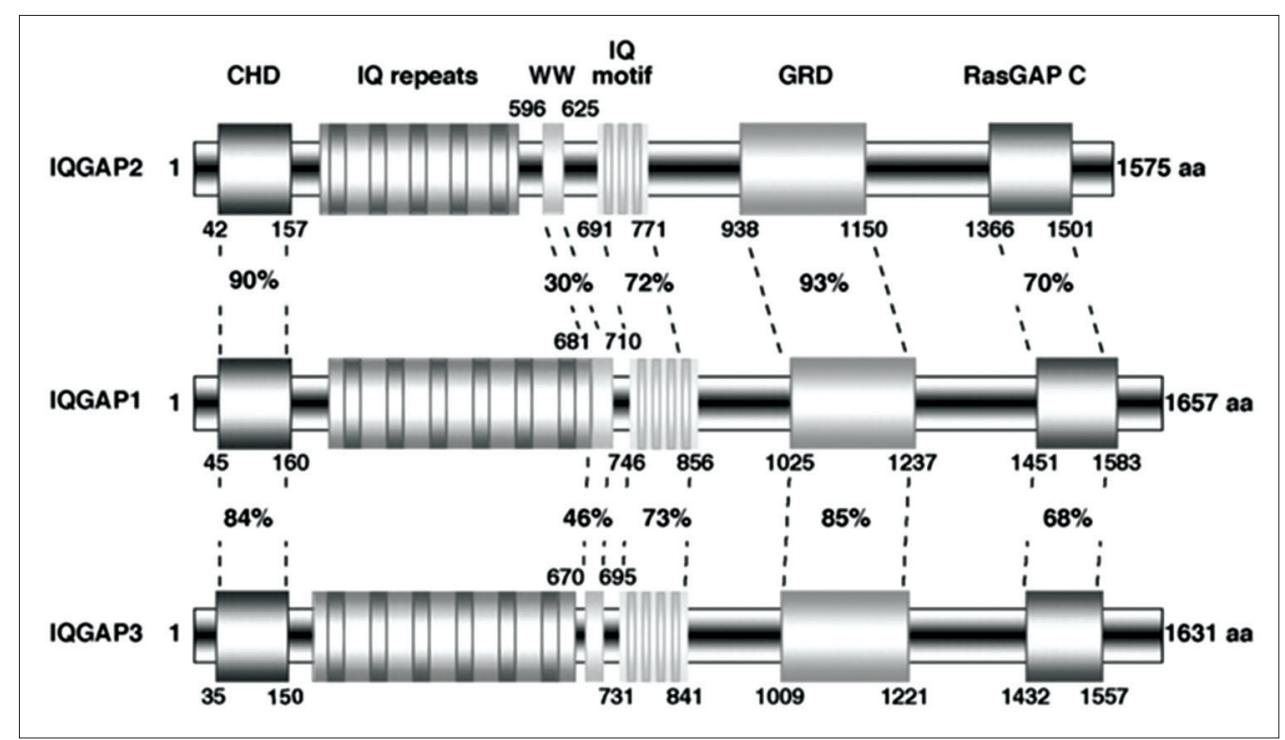

Fig. 1: Schematic diagram of the IQ-domain GTPase-activating proteins (IQGAP) family. The domain structures and the amino acid homologies are shown. CHD, calponin homology domain; IQ repeats, IQGAP-specific repeats; IQ motif, a calmodulin-binding motif; GRD,

RasGAP-related domains; RasGAP C, RasGAP C terminus. Adapted from Wang et al. [17]

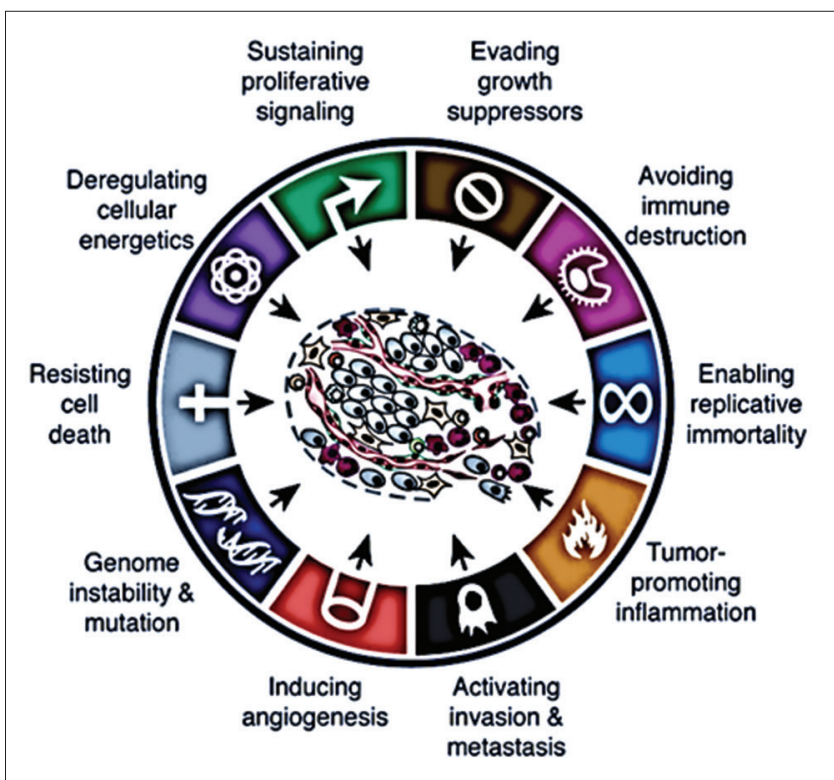

Fig. 2: The hallmarks of cancer. Adapted from Hanahan and Weinberg [38]

(MAPK) [41-46], receptor tyrosine kinases [27,47-49], receptor serine/ threonine kinases [50-52], and Wnt signaling pathways [53,54].

In vitro study using PANC-1 pancreatic ductal adenocarcinoma cell line shows that IQGAP1 binds with activated Rac1 that results in destabilization of E-cadherin-mediated adherens junctions, thus increase cell migration and invasion [36]. IQGAP1 was also reported to enhance cancer cell invasiveness by reducing cell-cell adhesion through an interaction with EGFP-MTA1 complex in the plasma membrane [34]. Using clinical samples of pancreatic carcinoma, Wang et al. also reported that the overexpression of IQGAP1 is obvious and associated with the grades of tumor differentiation [29]. Interestingly, the involvement of IQGAP1 in MAPK signaling cascade also reported to increase resistance to GEM [33].

Although less extensively studied, IQGAP3 was also reported to play a role in distinct cellular physiology; it was initially found to promote cell motility and migration by interaction with two Rho family GTPase proteins, Rac1 and Cdc42 [17]. Furthermore, a study by Nojima et al. showed that IQGAP3 is necessary to regulate normal cell proliferation through an interaction with ERK1 in Ras/ERK signaling cascade [55]. A comprehensive study by Xu et al. showed that increased expression of IQGAP3 was associated with larger tumor size, poorer differentiation, and increased incidence of metastasis; this could be due to decreased expression of E-cadherin, an important marker for epithelial-mesenchymal transition. Furthermore, siRNA-mediated knockdown of IQGAP3 increased the Caspase 3 and Caspase 9 level, indicating its relation with apoptosis regulation.

\section{IQGAP2 AND ITS TUMOR SUPPRESSIVE POTENTIALS IN PANCREATIC CANCER}

IQGAP2, first described in 1996, is predominantly expressed in the liver [11-13,23]. IQGAP2 was also reported to promote cell motility through binding to Rac1 and Cdc42 [12]. Furthermore, this protein is also found to regulate actin polymerization [56]. In addition, Schmidt et al. reported that IQGAP2 plays an important role in $\mathrm{Wnt} / \beta$-catenin signaling pathway.

Unlike IQGAP1 and IQGAP3, several studies showed that IQGAP2 might eventually suppress tumor progression. Downregulated expression of IQGAP2 was evident in hepatocellular carcinoma; this phenomenon was linked to the modulation of Wnt/ $\beta$-catenin pathways [21]. In addition, inactivation of IQGAP2 through promoter methylation was observed in gastric cancer, further leading to tumor progression and poor clinical outcome [19]. Moreover, forced expression of IQGAP2 significantly upregulates E-cadherin expression by suppressing AKT activation, thus hinder metastasis progression in prostate cancer [28].

The prognostic biomarker potential in pancreatic cancer was observed through a clinical study by Zeng et al. showing that the expression of IQGAP2 was associated with increased survival rates in pancreatic cancer patients who underwent radiotherapy [37]. Unfortunately, no more investigation about its tumor-suppressing ability in pancreatic cancer was published until recently. We propose that in vitro and in vivo study using IQGAP2 knockout mice might be necessary to confirm its role in pancreatic cancer.

\section{CONCLUSION}

Pancreatic cancer remains one of the deadliest malignancies in Indonesia and the world; therefore, seeking a new early diagnosis marker might 
eventually decrease its mortality rate. IQGAP family proteins raised an intention in cancer research due to their role in tumorigenesis. While IQGAP1 remains the most well-characterized among IQGAPs, there is still less known about the detailed role of IQGAP2 and IQGAP3 in pancreatic cancer. IQGAPs share similar domain composition; however, their role is interestingly distinct. IQGAP1 and IQGAP3 promote tumor proliferation and invasiveness, but IQGAP2 acts as a tumor suppressor gene. Furthermore, the upregulated expression of IQGAP2 might result in better prognosis in clinical data. Nevertheless, investigating more specific mechanisms of IQGAP proteins, especially IQGAP2 and IQGAP3, are necessary to further clarify their potentials in pancreatic cancer.

\section{AUTHORS' CONTRIBUTIONS}

Anton Sumarpo, Gisella Edny Tjugianto, David Agustriawan, Kenny Yonathan, and Agnes Anania Triavika Sahamastuti conceptualized the outline arrangement and writing. Anton Sumarpo also contributed in reviewing and finalized the manuscript preparation.

\section{CONFLICTS OF INTEREST}

The authors declare that they have no conflicts of interest.

\section{REFERENCES}

1. Ferlay J, Soerjomataram I, Dikshit R, Eser S, Mathers C, Rebelo M, et al. Cancer incidence and mortality worldwide: Sources, methods and major patterns in GLOBOCAN 2012. Int J Cancer 2015;136:E359-86.

2. Pelosi E, Castelli G, Testa U. Pancreatic cancer: Molecular characterization, clonal evolution and cancer stem cells. Biomedicines 2017;5: pii: E65.

3. Bardeesy N, DePinho RA. Pancreatic cancer biology and genetics. Nat Rev Cancer 2002;2:897-909.

4. Pourhoseingholi MA, Ashtari S, Hajizadeh N, Fazeli Z, Zali MR. Systematic review of pancreatic cancer epidemiology in asia-pacific region: Major patterns in GLOBACON 2012. Gastroenterol Hepatol Bed Bench 2017;10:245-57.

5. Ahrendt SA, Pitt HA. Surgical management of pancreatic cancer. Oncology (Williston Park) 2002;16:725-34

6. Ghaneh P, Costello E, Neoptolemos JP. Biology and management of pancreatic cancer. Gut 2007;56:1134-52.

7. Fukushige S, Horii A. Road to early detection of pancreatic cancer: Attempts to utilize epigenetic biomarkers. Cancer Lett 2014;342:231-7.

8. Amanam I, Chung V. Targeted therapies for pancreatic cancer. Cancers (Basel) 2018;10: pii: E36.

9. Ishii H, Furuse J, Nagase M, Yoshino M. Impact of gemcitabine on the treatment of metastatic pancreatic cancer. J Gastroenterol Hepatol 2005;20:62-6.

10. Kelley RK, Ko AH. Erlotinib in the treatment of advanced pancreatic cancer. Biologics 2008;2:83-95.

11. Smith JM, Hedman AC, Sacks DB. IQGAPs choreograph cellular signaling from the membrane to the nucleus. Trends Cell Biol 2015;25:171-84

12. Briggs MW, Sacks DB. IQGAP proteins are integral components of cytoskeletal regulation. EMBO Rep 2003;4:571-4.

13. White CD, Brown MD, Sacks DB. IQGAPs in cancer:A family of scaffold proteins underlying tumorigenesis. FEBS Lett 2009;583:1817-24.

14. Johnson M, Sharma M, Henderson BR. IQGAP1 regulation and roles in cancer. Cell Signal 2009;21:1471-8.

15. Weissbach L, Settleman J, Kalady MF, Snijders AJ, Murthy AE, Yan YX, et al. Identification of a human rasGAP-related protein containing calmodulin-binding motifs. J Biol Chem 1994;269:20517-21.

16. Brill S, Li S, Lyman CW, Church DM, Wasmuth JJ, Weissbach L, et al. The ras GTPase-activating-protein-related human protein IQGAP2 harbors a potential actin binding domain and interacts with calmodulin and rho family GTPases. Mol Cell Biol 1996;16:4869-78.

17. Wang S, Watanabe T, Noritake J, Fukata M, Yoshimura T, Itoh N, et al. IQGAP3, a novel effector of rac1 and $\operatorname{cdc} 42$, regulates neurite outgrowth. J Cell Sci 2007;120:567-77.

18. Huang L, Xu S, Hu D, Lu W, Xie X, Cheng X, et al. IQGAP1 is involved in enhanced aggressive behavior of epithelial ovarian cancer stem celllike cells during differentiation. Int J Gynecol Cancer 2015;25:559-65.

19. Jin SH, Akiyama Y, Fukamachi H, Yanagihara K, Akashi T, Yuasa Y, et al. IQGAP2 inactivation through aberrant promoter methylation and promotion of invasion in gastric cancer cells. Int $\mathrm{J}$ Cancer
2008:122:1040-6

20. Wang XX, Wang K, Li XZ, Zhai LQ, Qu CX, Zhao Y, et al. Targeted knockdown of IQGAP1 inhibits the progression of esophageal squamous cell carcinoma in vitro and in vivo. PLoS One 2014;9:e96501.

21. Schmidt VA, Chiariello CS, Capilla E, Miller F, Bahou WF. Development of hepatocellular carcinoma in iqgap2-deficient mice is IQGAP1 dependent. Mol Cell Biol 2008;28:1489-502.

22. Xia FD, Wang ZL, Chen HX, Huang Y, Li JD, Wang ZM, et al. Differential expression of IQGAP1/2 in hepatocellular carcinoma and its relationship with clinical outcomes. Asian Pac J Cancer Prev 2014; 15:4951-6.

23. White CD, Khurana H, Gnatenko DV, Li Z, Odze RD, Sacks DB, et al. IQGAP1 and IQGAP2 are reciprocally altered in hepatocellular carcinoma. BMC Gastroenterol 2010;10:125.

24. Kunimoto K, Nojima H, Yamazaki Y, Yoshikawa T, Okanoue T, Tsukita S, et al. Involvement of IQGAP3, a regulator of ras/ERKrelated cascade, in hepatocyte proliferation in mouse liver regeneration and development. J Cell Physiol 2009;220:621-31.

25. Chen F, Zhu HH, Zhou LF, Wu SS, Wang J, Chen Z, et al. IQGAP1 is overexpressed in hepatocellular carcinoma and promotes cell proliferation by akt activation. Exp Mol Med 2010;42:477-83.

26. Holck S, Nielsen HJ, Hammer E, Christensen IJ, Larsson LI. IQGAP1 in rectal adenocarcinomas: Localization and protein expression before and after radiochemotherapy. Cancer Lett 2015;356:556-60.

27. White CD, Li Z, Dillon DA, Sacks DB. IQGAP1 protein binds human epidermal growth factor receptor 2 (HER2) and modulates trastuzumab resistance. J Biol Chem 2011;286:29734-47.

28. Xie Y, Yan J, Cutz JC, Rybak AP, He L, Wei F, et al. IQGAP2, A candidate tumour suppressor of prostate tumorigenesis. Biochim Biophys Acta 2012;1822:875-84.

29. Wang XX, Li XZ, Zhai LQ, Liu ZR, Chen XJ, Pei Y, et al. Overexpression of IQGAP1 in human pancreatic cancer. Hepatobiliary Pancreat Dis Int 2013; 12:540-5.

30. Xu W, Xu B, Yao Y, Yu X, Cao H, Zhang J, et al. Overexpression and biological function of IQGAP3 in human pancreatic cancer. Am J Transl Res 2016;8:5421-32.

31. Matsunaga H, Kubota K, Inoue T, Isono F, Ando O. IQGAP1 selectively interacts with K-ras but not with $\mathrm{H}$-ras and modulates K-ras function. Biochem Biophys Res Commun 2014;444:360-4.

32. Jin Y, Lv X, Zhou J, Chen J. Potential involvement of IQGAP1 in proliferation and metastasis of human pancreatic cancer. Front Biosci (Landmark Ed) 2016;21:1076-83.

33. Jin X, Pan Y, Wang L, Ma T, Zhang L, Tang AH, et al. Fructose-1,6bisphosphatase inhibits ERK activation and bypasses gemcitabine resistance in pancreatic cancer by blocking IQGAP1-MAPK interaction. Cancer Res 2017:77:4328-41.

34. Hofer MD, Menke A, Genze F, Gierschik P, Giehl K. Expression of MTA1 promotes motility and invasiveness of PANC-1 pancreatic carcinoma cells. Br J Cancer 2004:90:455-62

35. Osman MA, Sarkar FH, Rodriguez-Boulan E. A molecular rheostat at the interface of cancer and diabetes. Biochim Biophys Acta 2013; 1836:166-76

36. Hage B, Meinel K, Baum I, Giehl K, Menke A. Rac1 activation inhibits E-cadherin-mediated adherens junctions via binding to IQGAP1 in pancreatic carcinoma cells. Cell Commun Signal 2009;7:23.

37. Zeng H, Yu H, Lu L, Jain D, Kidd MS, Saif MW, et al. Genetic effects and modifiers of radiotherapy and chemotherapy on survival in pancreatic cancer. Pancreas 2011;40:657-63.

38. Hanahan D, Weinberg RA. Hallmarks of cancer: The next generation. Cell 2011;144:646-74

39. Noritake J, Watanabe T, Sato K, Wang S, Kaibuchi K. IQGAP1: A key regulator of adhesion and migration. J Cell Sci 2005;118:2085-92.

40. Wehrle-Haller B. Assembly and disassembly of cell matrix adhesions. Curr Opin Cell Biol 2012;24:569-81.

41. Kimura T, Yamaoka M, Taniguchi S, Okamoto M, Takei M, Ando T, et al. Activated cde42-bound IQGAP1 determines the cellular endocytic site. Mol Cell Biol 2013;33:4834-43.

42. Roy M, Li Z, Sacks DB. IQGAP1 binds ERK2 and modulates its activity. J Biol Chem 2004;279:17329-37.

43. Roy M, Li Z, Sacks DB. IQGAP1 is a scaffold for mitogen-activated protein kinase signaling. Mol Cell Biol 2005;25:7940-52.

44. Ren JG, Li Z, Sacks DB. IQGAP1 integrates ca2+/calmodulin and B-raf signaling. J Biol Chem 2008;283:22972-82.

45. Ren JG, Li Z, Sacks DB. IQGAP1 modulates activation of B-raf. Proc Natl Acad Sci U S A 2007;104:10465-9.

46. Sbroggiò M, Carnevale D, Bertero A, Cifelli G, De Blasio E, Mascio G, 
et al. IQGAP1 regulates ERK1/2 and AKT signalling in the heart and sustains functional remodelling upon pressure overload. Cardiovasc Res 2011;91:456-64.

47. Yamaoka-Tojo M, Ushio-Fukai M, Hilenski L, Dikalov SI, Chen YE, Tojo T, et al. IQGAP1, a novel vascular endothelial growth factor receptor binding protein, is involved in reactive oxygen speciesdependent endothelial migration and proliferation. Circ Res 2004;95:276-83.

48. McNulty DE, Li Z, White CD, Sacks DB, Annan RS. MAPK scaffold IQGAP1 binds the EGF receptor and modulates its activation. J Biol Chem 2011;286:15010-21

49. Kohno T, Urao N, Ashino T, Sudhahar V, Inomata H, Yamaoka-Tojo M, et al. IQGAP1 links PDGF receptor- $\beta$ signal to focal adhesions involved in vascular smooth muscle cell migration: Role in neointimal formation after vascular injury. Am J Physiol Cell Physiol 2013;305:C591-600.

50. Liu C, Billadeau DD, Abdelhakim H, Leof E, Kaibuchi K, Bernabeu C, et al. IQGAP1 suppresses t $\beta$ RII-mediated myofibroblastic activation and metastatic growth in liver. J Clin Invest 2013;123:1138-56.
51. Feigin ME, Xue B, Hammell MC, Muthuswamy SK. G-proteincoupled receptor GPR161 is overexpressed in breast cancer and is a promoter of cell proliferation and invasion. Proc Natl Acad Sci U S A 2014;111:4191-6.

52. Neel NF, Sai J, Ham AJ, Sobolik-Delmaire T, Mernaugh RL, Richmond A, et al. IQGAP1 is a novel CXCR2-interacting protein and essential component of the "chemosynapse". PLoS One 2011;6:e23813.

53. Goto T, Sato A, Shimizu M, Adachi S, Satoh K, Iemura S, et al. IQGAP1 functions as a modulator of dishevelled nuclear localization in wnt signaling. PLoS One 2013;8:e60865.

54. Carmon KS, Gong X, Yi J, Thomas A, Liu Q. RSPO-LGR4 functions via IQGAP1 to potentiate wnt signaling. Proc Natl Acad Sci U S A 2014;111:E1221-9.

55. Nojima $\mathrm{H}$, Adachi $\mathrm{M}$, Matsui $\mathrm{T}$, Okawa $\mathrm{K}$, Tsukita $\mathrm{S}$, Tsukita $\mathrm{S}$, et al. IQGAP3 regulates cell proliferation through the ras/ERK signalling cascade. Nat Cell Biol 2008;10:971-8.

56. Schmidt VA, Scudder L, Devoe CE, Bernards A, Cupit LD, Bahou WF, et al. IQGAP2 functions as a GTP-dependent effector protein in thrombininduced platelet cytoskeletal reorganization. Blood 2003;101:3021-8. 